\title{
Papers Presented at the Symposium on the Ionospheric Propagation of VLF Radio Waves
}

\section{Preface}

\author{
D. D. Crombie \\ Chairman, Program Committee
}

\begin{abstract}
Some of the reasons for holding a symposium on VLF propagation are noted and areas of progress since a previous symposium are indicated.
\end{abstract}

Although the earliest long-distance communications were performed with the aid of verylow-frequency $(3-30 \mathrm{kc} / \mathrm{s})$ radio waves, these frequencies fell into relative disuse in the middle 1920's. This was because Marconi and others showed that communication over long distances could be obtained more economically by the use of high frequency $(3-30 \mathrm{Mc} / \mathrm{s})$ signals, although with lower reliability. This situation remained until about the 1950's when some of the attractive features of VLF communication, such as relative immunity to ionospheric disturbances, remarkably high phase stability, relatively easy penetration into sea water, etc., began to outweigh the disadvantages for certain purposes. Among the disadvantages can be listed the large, expensive transmitter antennas, the high natural noise background, narrow bandwidth of transmitting antennas, and small total available bandwidth. Some of the present interesting applications of VLF transmissions include their use in long-range phase comparison navigational aids, comparison and dissemination of frequency standards, and their use for the study of perturbations, both natural and manmade, of the lower ionosphere.

In 1957 the first conference devoted to VLF propagation was held in Boulder. Because of the considerable success of this meeting, and of the great advances made in theoretical problems in this field, a second symposium was held at the Central Radio Propagation Laboratory, National Bureau of Standards, Boulder, Colo., August 12, 13, and 14, 1963 . Of the nearly 50 papers presented during the symposium, some 20 are included either fully or in summary form in this issue ${ }^{1}$ of "Radio Science." It is expected that some of the other papers presented at the symposium will appear in subsequent issues.

The papers included here show the considerable strides that have been made both experimentally and theoretically since the earlier symposium. Experimentally, it is clear that techniques for the observation of variations in phase delay are now well established and are receiving wide use. On the other hand, it seems that more observations could be made of signal strength, since in several instances observations made in 1922 were quoted. Papers presented at the symposium appear to have removed any remaining doubts as to whether nonreciprocal propagation can be expected, and confirmed earlier estimates of the magnitude of this effect. The theoretical papers were concerned with the consequences of recognizing that the ionosphere is not sharply bounded, but included calculations relating to the effects of the earth's magnetic field on reciprocity. Another group of papers was concerned with the relatively new field of the effect of high-altitude nuclear explosions on the propagation of VLF radio waves.

During a special session at the symposium, Dr. Astin, Director of NBS, dedicated the new NBS standard frequency and time transmitting station, which is situated at Ft. Collins, Colo. This session also included papers dealing with the utilization, technical design, and construction of the station.

${ }_{1}^{1}$ Papers received August 24, 1963. 
The holding of the symposium itself was due to the enthusiastic support and valuable advice of J. S. Belrose, W. T. Blackband, J. K. Hargreaves, R. A. Helliwell, G. E. Hudson, A. G. Jean, and, particularly, J. R. Wait. Members of the National Bureau of Standards staff who were also generous with their help and to whom credit for the organizational arrangements is due are Mrs. D. Belsher, Mrs. S. M. Platt, J. B. Reubens, R. T. Frost, J. A. Kemper, M. A. Mulligan, and R. E. Sodergren.

Great credit is due to Mildred F. Talbutt, Editorial Secretary, for her sterling effort in preparing the papers in time for publication in this issue of "Radio Science." 